\title{
The Political Representation of Time in Museum
}

\author{
Yan Jiang \\ College of Literature and Journalism, Sichuan University, Chengdu 610061, China \\ yanjiang1019@163.com
}

\begin{abstract}
In exploring the history of museum, people usually trace back to the "cabinets of curiosities" as its origin, which however is only one of the many possible perspectives. The historian Fernand Braudel designates his approach to the study of history with "the long term", "the medium term" and "the short term", which provides us with different angles in viewing history. When we put museum the public space of preserving and protecting artworks under the perspective of "the medium term" which allows a longer duration in time line, rather than "the short term" which often refers to historical moments and events. Obviously, under such perspective, what jumps into people's horizon is the church. And the easel painting played the role of the agent who transferred artworks from church to museum. The change of space is a representation of the will and power of the ruling class. Through investigating the evolution of the church, easel painting, artworks and museum, and tracing their social and historical conditions, this article reveals the modern process of human beings in time and provides a new perspective of reflecting museum.
\end{abstract}

Keywords: museum, time, church, the easel painting.

\section{博物馆的时间政治学}

\section{蒋岩}

武侯区丽都路16号时代丽都美语3栋2单元806, 四川成都, 中国.

摘 要：人们在考察博物馆的历史时，通常认为 17 世纪的“奇珍楃 柜” (cabinets of cur iosities) 是其雏形, 认为博物馆经历了从私自占有到向公众开放的历 史转变。然而, 历史学家布罗代尔在考察历史事件时, 认为可用“长时段”、“中时段”、 “短时段” 三种眼光观之。当我们把博物馆这种保护、储藏艺术品和文物的公共空间形态放 到“中时段” 的视域里考察, 而非“短时段” 的历史时刻的跳跃, 就会在时间轴上将之往前 挪移。很显然, 跃进我们视野里的就是教堂这种公共文化空间。艺术品从教堂到博物馆, 是 以 “架上画” 作为中介, 背后有其深刻的社会历史渊源。这种时空更替, 是统治阶级和权力 意志的体现, 是对政治学和人类进程的表征。本文通过考察教堂、架上画、博物馆, 以及艺 术品的演变，通过追溯其社会历史根源，展现了时间下的人类现代进程，提供了一个观照博 物馆的新视角。

关键词：博物馆, 时间, 教堂, 架上画, 表征.

\section{1. 博物馆与时间}

人们在考察博物馆的历史时，一般会追溯两种源头：一种是博物馆的实体源头; 另一种是博 物馆的名字来源。人们通常认为博物馆起源于 “奇珍棏柜” (cabinets of curiosities) 一皇 家贵族用于收藏 “奇珍异宝” 的地方。16世纪晚期到 17 世纪, 贵族、学者、富有的商人艺术 家、内科医生以及药剂师成为博物馆的先驱者。根据胡珀一格林希尔的说法, 奇珍梪柜在人类 的微观世界、上帝的宏观世界以及宇宙之间起着调停作用, 但 “奇珍橱柜是私人空间而非博 物馆” [1]。在奇珍梪柜发展的那段时间，“博物馆”（Museum）一词很少提及。“Museum” 一词来源于希腊语 “Mouseion” , 意即缪斯（Muse）女神的位置或神庙，与文化艺术品及其研 究相关联。公共博物馆的诞生, 源于启蒙运动和资产阶级革命的推动。公共博物馆的建立, 曝光了之前作为私藏的 “奇珍异宝” ，它 “既揭露了古老的统治形式即古代统治的腐朽与暴 
政，又展现了新的统治形式即共和政体的民主与公益性”。法国大革命以人民的名义没收了 王室、贵族、教会的收藏品，从而把博物馆从专制权力的象征变成一种教育公民而服务于国 家的利益工具。 [2]

时间是一个古老的话题。人们对时间的感受并非古来一致。永恒时间与世俗时间概念的对立， 即是神话系统与宗教系统中神和人的对立。四季的更替往复, 则让人相信循环时间的存在。 线性时间不过是近代科学运动产生的观念。历史学家布罗代尔在考察时间问题时, 认为传统 历史学所感兴趣的是传记和事件这样的历史学的短时段。但是, 随着社会发展, 价格曲线、 人口级数工资运动、利率变动、生产力研究等都需要有更大的量器。由此, 他发展了三种看 待历史的眼光：短时段、中时段和长时段。 [3] 当我们以 “短时段” 观照博物馆, 其焦点在于 从 “奇珍梪柜” 转变成公共博物馆、藏品 “珍宝” 演变成博物馆中的展品这一历史事件。博 物馆成为收藏、保护文物的公共文化空间。然而，当我们把目光从 “短时段” 转换成 “中时 段” 时，博物馆这种公开性的、聚合大众参与并持有大量艺术品的空间，在此之前实际上是 以另一种形态存在一教堂。

\section{2. 教堂、艺术与权力}

教堂是基督信徒进行宗教仪式的地方，聚集了各种艺术形态，如建筑、绘画、雕塑、音乐等。 然而，教堂能成为中世纪与文艺复兴时期艺术汇集的空间，与权力的结合是分不开的。在基 督信徒为其信仰东奔西走甚至殉道的时期，他们并没有一个固定的宣扬信仰和进行礼拜的公 共空间，常常流离失所并被统治阶级迫害。

4 世纪初, 君士坦丁在争夺罗马帝国皇权中取得胜利。从 312 年开始, 君士坦丁公开表示归信 基督教并规定星期日为公共假日，这对于基督教的发展产生了巨大的影响。自此，辉煌的教 会建筑拔地而起。[4] “巴伐利卡” (basilicas) 式教堂是基督教堂的早期形式。巴西利卡 是古典文化时期的大型会堂, 用做室内市场和公开法庭。大殿是长方形, 沿着两条长边有些 比较狭窄、低矮的分隔间，由一排柱子把它们跟大殿隔开。殿内半圆形的拿被当作主祭坛。

[5]唱诗班席、中殿、侧廊等教堂功能分区，从早期教堂开始就已形成。因此，从基督教被统 治者所青睐伊始，教堂这一建筑就深深打上了权力的烙印。宗教与艺术的同源和同一性，在 权力的介入之后, 得到了巩固。然而, 艺术与民众的关系却悄然改变。在权力介入之前, 是 狂欢化的庆典, 是兴奋与狂喜的自然流露; 而在权力介入之后, 民众与艺术拉开了距离, 不 再是完全的参与者, 而是匍匐在地, 被宗教艺术的崇高所震慑。

查士丁尼是第二位强力支持基督教的皇帝。在他的统治下，东正教拜占庭的特征越发明显。 他支持重建君士坦丁的圣智院即索菲亚教堂。“同时代人说，该堂半圆穹顶可以说是由一根 来自天国的链条悬挂起来的, 这根链条就是一根有等级的连接物, 向上可以从有限升至无限, 向下可以从创造者降至受造界。它看上去像天空一样高不可测。” [6]查士丁尼运用其权力, 从埃及、利比亚、希腊、小亚细亚的弗里吉亚等地运来各色的大理石、花岗岩, 使圣索菲亚 大教堂显得美轮美负。这是个人的力量所不能达到的。除了圣索菲亚大教堂, 查士丁尼还支 持兴建其他许多教堂, 分布在帝国各处, 以显示他无所不在的权力一包括巴尔干半岛、巴勒 斯坦、北非以及意大利，甚至在荒凉的西奈山坡上。

艺术赞助是权力介入教堂艺术的另一表现形式。赞助人除了订购艺术家的作品, 他们的兴趣 和要求也会对艺术家产生具体的影响。文艺复兴时期, 赞助体制盛行, 其中以美第奇家族最 富盛名。这个统治了佛罗伦萨四百多年的家族, 产生了三位教皇、七位托斯卡纳大公、两位 法国皇后。美第奇家族赞助过的艺术家有马萨乔、多那太罗、波提切利、达・芬奇、拉菲尔、 德拉瑞亚、米开朗琪罗、提香、曼坦尼亚等等。很难想象, 如果没有赞助者的委托和赞助, 达・芬奇会在圣玛利亚慈悲修道院的墙壁上去画《最后的晚餐》, 米开朗琪罗会画出他的鸿 篇巨制一西斯廷礼拜堂天顶画，拉斐尔会去梵蒂冈宫绘制《雅典学院》。

至于美第奇家族赞助艺术的原因, 其中不乏个人荣耀和兴趣、宗教救赎、良心慰藉等, 然而, 政治扩张和控制方式却是其中最重要的原因。乔凡尼从古老的社团宗教生活传统中看到了资 
助艺术的重要性, 并积极投身其中, 奠定了美第奇家族获得政治地位的基础。正如贡布里希 所说，“赞助确实是美第奇家族政治中的一个主要手段。”[7]

可见, 从中世纪到文艺复兴时期, 教堂建筑本身及其雕塑和壁画, 都深深地打上了权力的印 记。

\section{3. 架上画: 教堂到博物馆的中介}

从教堂向博物馆的转变过程中, 在教堂的各种艺术形态成为博物馆的展品过程中, 架上画 (ease1 painting) 起着关键的过渡作用。架上画的出现, 根源于教堂的祭坛画一绘制在祭 坛的木板上。它诞生于14-15世纪的尼德兰, 是与壁画和祈祷书上的装饰插图有别的另一种 绘画形式。当时的尼德兰包括现在的荷兰、比利时、卢森堡及法国的东北部地区, 其地理位 置优越, 手工业、商业等新兴资本主义经济繁荣。尼德兰资产阶级革命之后建立了资产阶级 共和国。城市手业和商业的进一步发展, 催生了市民阶层、资产阶级的产生。在拥有一定的 经济积累之后, 新兴资产阶级对于文化艺术的需求也日益凸显。以往的艺术属于教堂, 如壁 画、祭坛木板画、祈祷书插图等。在格林伯格看来, 教堂之外几乎没有艺术, “自从旧石器 时代以来, 欧洲的 “民众’ 运用色彩和线条所做的, 不外乎装饰而已。” [8]而木板画从祭坛 走下来, 是适应新兴市民阶级出现而产生的审美趣味所致。

同一时期, 南方的意大利, 文艺复兴也如火如茶地展开。意大利最早研究并掌握油画技法的 画家安东奈洛 - 达 - 梅西纳, 据说是在去尼德兰了解到凡 - 艾克兄弟的油画技法之后, 回到 威尼斯传授油画颜料使用方法。自此油画家随着油画作为一个独立的画种, 在欧洲大陆的流 行而产生。[9]

与绘画媒介一同改变的, 还有绘画的主题和风格。与之前的宗教和神话题材不同, 架上画的 产生使肖像画、静物画、风景画乃至风俗画得以独立出现于画坛, 它甚至使美术教学从早期 壁画的师徒传授方式转向画室和学院教学, 到19世纪, 学院教学的方法、手段、目的均以架 上画形式为主。绘画逐渐从宗教走向世俗。

\section{4. 博物馆与权力}

架上画的出现, 使艺术不再依附于建筑（教堂）或者建筑中的某固定物（如祭坛）。便于携 带的架上画, 也使艺术品收藏得以实现。第一个现代意义上的博物馆是始建于 1560 年的乌菲 齐美术馆。而具有现代意义上的公共博物馆产生于17世纪后期, 以1683 年英国牛津大学阿什 莫林艺术和考古博物馆向公众开放为代表。之后, 大英博物馆和卢浮宫分别于 1759 年与 1793 年相继对公众开放, 意味着公共博物馆时代的真正到来, 也象征着博物馆教育正式走到了公 众面前。美国学者邓肯曾写到: “在理论上说, 博物馆是参观者获得精神提升的公共空间。 然而, 它们实际上又是意识形态的强有力的机器, 举足轻重。”

法国作家德吉安说：“文化政策是法国人的发明”。[11]法国政府有着一种强烈的文化使命 感, 自旧制度时代起一直沿袭文化干预的政治传统。“法国文化政策的历史可上溯到16世纪 的皇室赞助传统, 从那时直到今天, 以国家的核心角色为标志：即促进并管治知识（法兰西 学术院, 国家图书馆) 、艺术 (国家歌剧院、卢浮宫博物馆) 和文化, 逐步完善国家文化行政 管理机构和文化预算（创建于19世纪的美术司和1959年的文化部）。”[12]

由此可见, 公共博物馆在其形成和发展历程中, 显而易见受制于权力和政治目的的驱使。现 代博物馆也并非中立的机构, 仍在延续权力的意志体现。它所发挥的教育、展览等功能, 实 际上 “是一个精心设计的国家建筑物的教学法工具。它的目标是在现代公民还未意识到它之 前就塑造他们, 这些人具有爱国心, 是 “文明人”, 有审美意识, 是纯血统的, 而且易受控 制。”[13]. 


\section{5. 表征及结语}

历史上, 教堂和博物馆都担当了艺术品集聚和存在的公共空间这一角色。从教堂艺术, 到架 上画, 再到博物馆, 这一延续的转变背后, 其支配力量是统治阶级的统治和管理。以博物馆 为载体的文化资本被统治阶层所占有、自上而下地扩散。斯图亚特 - 霍尔认为文化中存在 “表 征系统”，他阐释了表征的概念：通过在各种事物（人、物、事、抽象观念等等）与我们的概 念系统、概念图之间建构一系列相似性或一系列等价物。[14] 时间流动之下，艺术从教堂到 架上画、再到博物馆, 就是一种政治学的表征。

如今, 架上画亦面临其危机, 它自身携带的边框、构图等艺术法则被现代主义运动的艺术行 为一次次打破, 消解 “边界” 的呼声越来越高。与之相伴的, 是对博物馆 “父权制” 统治的质 疑和批判。从某种意义上来讲, 教堂到博物馆这一跨越千年的文化资本的流动, 实际是对社 会转型、阶级更替以及人类现代进程的一种表征。从这个角度来看博物馆, 我们或许会有不 一样的认识。

\section{References}

[1]. Marstine, Janet. New Museum Theory and Practice: An Introduction. Trans, Qian Chunxia et al. Jiangsu Fine Arts Publisher, 2008, p.p.27-28.

[2]. See Bennett, Tony. Culture and Society. Trans, Wang Jie et al. Guangxi Normal University Press, 2007, p.217.

[3]. See Braudel, Fernand. On History. Trans, Liu Beicheng and Zhou Lihong. Beijing University Press, 2008, p.82.

[4]. See Shelley, Bruce. Church History in Plain Language. Trans, Liu Ping. Beijing University Press, 2004, p.p.100-101.

[5]. E.H. Gombrich. The Story of Art. Trans, Fan Jingzhong. Guangxi Fine Arts Publisher, 2008, p.133.

[6]. Shelley, Bruce. Church History in Plain Language. Trans, Liu Ping. Beijing University Press, 2004, p.p.161-162.

[7]. E. H. Gombrich. The Renaissance: The Great Era of Western Art. China Academy of Art Press, 2000, p.150.

[8]. Greenberg, Clement. Art and Culture. Trans, Shen Yubing. Guangxi Normal University Press, p.178.

[9]. See Han, Hongwei. The Research on the Brushwork of Oil Painting. Dissertation. Chinese National Academy of Arts, China, 2009, p.5.

[10]. Duncan, Carol. Civilizing Rituals- Inside Public Art Museums, Routledge Taylor and Francis Group, 1995, p.2.

[11]. Looseley, David. Cultural Policy in France Since1959, Nordic Cultural Institute, 2001, p.26.

[12]. Cao, Yiqiang. Art and History. China Academy of Art Press, 2001.

[13]. Marstine, Janet. New Museum Theory and Practice: An Introduction, Jiangsu Fine Arts Publisher, 2008, p.30.

[14]. Hall, Stuart. Representation: Cultural Representations and Signifying Practice. Trans, Xuliang and $\mathrm{Lu}$ Xinghua. The Commercial Press, 2003, p.19. 